\title{
Primary Care and Primary Care Training: Mirror Images
}

\author{
Eric J. Warm, $M D^{7}$ and Emily Leasure, $M D^{2}$ \\ 'Department of Internal Medicine, University of Cincinnati Academic Health Center, Cincinnati, OH, USA; ${ }^{2}$ Department of Internal Medicine, \\ University of Cincinnati Academic Health Center, Cincinnati, OH, USA.
}

J Gen Intern Med 26(1):5-7

DOI: $10.1007 / \mathrm{s} 11606-010-1561-0$

(c) Society of General Internal Medicine 2010

"It's a poor sort of memory that only works backward." Lewis Carroll, Through the Looking Glass

Primary care appears to be in a perpetual state of crisis. The failures are well known. Primary care physicians work in stressful, under-resourced work environments with overcrowded schedules geared towards acute care. ${ }^{1}$ Chronic disease patients receive inadequate treatment ${ }^{2,3}$ and physicians lack the time, expertise and money to systematically measure and improve the quality of care they deliver. ${ }^{4}$ Despite this, physician salary and reputation are being increasingly based on these measures. It is not difficult to imagine why so many primary care physicians burnout and quit practice within a few years after training and why medical school graduates are not pursuing primary care careers.

Reasons for these failures abound. Fee for service models incentivize quantity over quality and do not reward cognitive effort and care coordination. Acute care and large patient panel sizes make it nearly impossible for physicians to provide all recommended chronic and preventative care. Lack of effective healthcare teams leads to uncontrollable work-life balance issues. In this month's Journal of General Internal Medicine, Nadkarni and colleagues discover that training programs may be part of the problem. ${ }^{5}$

In his study, Nadkarni finds that residents care for ill and disadvantaged patients in inadequately resourced clinics, with little use of quality improvement techniques, and that resident practices are often highly stressful and a fail to meet regulatory requirements.

\section{Sound familiar?}

Perhaps this is an echo of Berwick's famous line, "Every system is perfectly designed to achieve the results it achieves." Many authors have described a training-practice gap, but seen through the eyes of studies like Nadkarni's, there doesn't appear to be much of a difference between the two. Like a set of opposing mirrors, primary care training and practice are

Published online November 10, 2010 reflections in dysfunction-training looks like practice, and practice looks like training, ad infinitum. The real gap lies between what physicians actually do and what must be done. ${ }^{4}$

Just like reflections in a mirror, primary care training and practice must change simultaneously. If reform doesn't occur for our trainees, then reform on a national scale will likely falter.

The prevailing sentiment during calls for reform is usually 'the time is now!' or 'this time it's different!' But maybe the time really is now, and it really is different. Never before have so many converging forces aligned for change. In practice, the Patient Protection and Affordable Care Act, the Patient Centered Medical home (PCMH), and the rise of electronic health records have dramatically altered our view of ideal ambulatory care. On the education front, virtually every major internal medicine society has put forth plans for reform. The most recent Accreditation Council for Graduate Medical Education (ACGME) requirements contain provisions to enact these plans, ${ }^{7}$ and the landmark book, Educating Physicians: A Call for Reform of Medical School and Residency ${ }^{8}$ echoes many of these sentiments.

Still, the work must be done. What might a transformed residency ambulatory practice look like? In 2009, the American Board of Internal Medicine defined the Comprehensive Care Internist ${ }^{9}$ and developed eight competencies, which if applied to trainees, might create a residency experience very different than that described in Nadkarni's study.

According to the ABIM, a Comprehensive Care Internist is:

1. An expert diagnostician and clinician-Nadkarni's study shows that most programs still schedule ambulatory clinics around inpatient schedules. Currently, 1/3 of residency training is required to be ambulatory, yet across the country a significant portion of ambulatory time is spent in non-continuity blocks, subspecialty clinics, and emergency department rotations. ${ }^{10}$ Specific primary care curricula should be as protected, well-developed, and prioritized as subspecialty and inpatient curricula, and ambulatory training schedules should be separated from inpatient demands.

2. A patient advocate-The program directors in Nadkarni's study describe dysfunctional care environments where residents often have to make avoidable personal sacrifices of time and effort to help patients. Instead, resident clinics should be team-based, supportive, and patient centered, making patient advocacy the norm rather than the exception. 
3. An effective communicator-Nadkarni's study shows that very few practices ask patients to evaluate resident physicians, despite many excellent tools available to do so. In addition, faculty evaluation of resident communication is often based on communication away from the patient or in simulated encounters. Resident practices must integrate both patient feedback and faculty assessment of true resident-patient encounters directly into daily workflow.

4. A team leader and an effective teammate-Although the respondents in Nadkarni's study listed many potential team members (nurses, social workers, nutritionists, etc.), the overwhelming sentiment of clinic directors was that true teamwork did not exist. And, a minority of residencies asked non-physician team members to evaluate the residents. Resident practices should develop effective teams that meet frequently, review patient outcomes, and improve care processes to optimize these outcomes. In addition, clinic directors should create robust 360 degree evaluations for all health care workers in the practice.

5. A systems manager and, 6. An effective change agentVery few clinic directors in Nadkarni's study felt they could easily make changes in the clinic, including those that concern operations, systems, and staff. If the clinic directors feel this way, how must the residents feel? As resident practices form inter-professional teams, clinic directors and residents should seek training in team effectiveness.

6. An effective user of health information technology and health data-Although electronic health records are becoming ubiquitous, fewer than $20 \%$ of clinic directors in Nadkarni's study reported using data-based quality improvement tools. Residencies must recognize that most electronic health records do not yet have robust data mining capabilities, and physicians should push for improving this capacity when possible. In addition, resident practices should develop expertise in using registry data to improve care.

7. A practitioner accountable for efficient, accessible careThe ACGME Outcomes Project ${ }^{11}$ stresses accountability in education, and ultimately, patient care. Once resident practices develop methods to capture data (quality, patient satisfaction, accessibility, etc.), they must then create a sense of true accountability and the capacity to continually improve results.

This seems like a daunting task. Indeed, a recent study suggested discordance between the acknowledgement of problems in ambulatory clinic and the desire to change from the status quo. ${ }^{12}$ Change is always resisted, but perhaps the residents and program directors in this study could only imagine more of the same, and not a truly transformed educational experience.

The good news is that examples are emerging of such a transformation. The national Academic/California Chronic Care Collaboratives showed that systematic practice and education redesign is achievable across disparate resident continuity clinics. ${ }^{13}$ To their delight, researchers found teams that achieved better outcomes on clinical indicators reported more professional work satisfaction. ${ }^{14}$ These papers point out an important first step in developing a transformed practicethe leaders of the practice must seek training in improvement techniques and be able to bring these concepts home to their institutions.

Other examples of transformed ambulatory resident practices include participants in the ACGME's Educational Innovations Project. ${ }^{15}$ These residencies have developed several new models of ambulatory training and have shown that largely separating inpatient and outpatient care can lead to improved patient satisfaction and outcomes. Following this lead, the new ACGME RRC-IM requirements mandate that residency programs develop models for ambulatory training that minimize conflicting inpatient and outpatient duties, include evaluation of individual practice based measures, include care coordination across health care settings, and provide continuous faculty mentorship to residents. ${ }^{7}$ In practice, PCMH demonstration projects are beginning to show efficacy and a significant energy continues to support medical home development. However, this energy comes at a premium in the costs and risks of re-training an already mature workforce. Success and sustainability will likely depend on residents already prepared to enter the medical home.

Primary care transformation will only occur if both the training and practice environments create their emergent futures together. If not, we will simply continue to see ourselves, unchanged, through the looking glass.

Corresponding Author: Eric J. Warm, MD; Department of Internal Medicine, University of Cincinnati Academic Health Center, 231 Albert Sabin Way, Cincinnati, OH 45267-0557, USA (email: warmej@ucmail.uc.edu).

\section{REFERENCES}

1. Bodenheimer T, Pham HH. Primary care: Current problems and proposed solutions. Health Aff (Millwood). 2010;29:799-805.

2. McGlynn EA, Asch SM, Adams J, et al. The quality of health care delivered to adults in the united states. N Engl J Med. 2003;348:263545.

3. Bodenheimer T, Wagner EH, Grumbach $\mathbf{K}$. Improving primary care for patients with chronic illness. JAMA. 2002;288:1775-9.

4. Casalino LP. Disease management and the organization of physician practice. JAMA. 2005;293:485-8.

5. Nadkarni M, Siddharta R, Bates C, Fosburgh B, Stewart B, Holmboe E. Ambulatory based education in internal medicine: Current organization and implications for transformation. J Gen Intern Med. 2011; doi: 10.1007/s11606-010-1437-3.

6. Berwick DM. A primer on leading the improvement of systems. BMJ. 1996;312:619-22.

7. Accreditation Council for Graduate Medical Education. ACGME Program Requirements for Graduate Medical Education in Internal Medicine. Available at: http://www.acgme.org/acWebsite/downloads/RRC_progReq/ 140_internal_medicine_07012009.pdf. Accessed 11/29, 2009.

8. Cooke M, Irby DM, O'Brien BC. Educating Physicians: A Call for Reform of Medical School and Residency. San Francisco California: Jossey-Bass; 2010.

9. American Board of Internal Medicine. Comprehensive Care Internal Medicine. Available at: http://ccimreport.org/report.html. Accessed October 11, 2010 
10. Zebrack JR, Fletcher KE, Beasley BW, Whittle J. Ambulatory training since duty hour regulations: A survey of program directors. Am J Med. 2010;123:89-94.

11. Accreditation Council for Graduate Medical Education. ACGME Outcome Project. Available at: http://www.acgme.org/outcome/comp/ compMin.asp. Accessed 11/4, 2010.

12. Thomas KG, West CP, Popkave C, et al. Alternative approaches to ambulatory training: Internal medicine residents' and program directors' perspectives. J Gen Intern Med. 2009;24:904-10.
13. Stevens DP, Bowen JL, Johnson JK, et al. A multi-institutional quality improvement initiative to transform education for chronic illness care in resident continuity practices. J Gen Intern Med. 2010;25(Suppl 4):S574-80.

14. Johnson JK, Woods DM, Stevens DP, et al. Joy and challenges in improving chronic illness care: Capturing daily experiences of academic primary care teams. J Gen Intern Med. 2010;25(Suppl 4):S581-5.

15. Mladenovic J, Bush R, Frohna J. Internal medicine's educational innovations project: Improving health care and learning. Am $\mathrm{J}$ Med. 2009;122:398-404. 